\title{
Article \\ Ultra-Flexible Organic Solar Cell Based on Indium-Zinc-Tin Oxide Transparent Electrode for Power Source of Wearable Devices
}

\author{
Jun Young Choi, In Pyo Park and Soo Won Heo * (D)
}

Citation: Choi, J.Y.; Park, I.P.; Heo, S.W. Ultra-Flexible Organic Solar Cell Based on Indium-Zinc-Tin Oxide Transparent Electrode for Power Source of Wearable Devices. Nanomaterials 2021, 11, 2633. https:// doi.org/10.3390/nano11102633

Academic Editor: Vlad Andrei Antohe

Received: 9 September 2021

Accepted: 3 October 2021

Published: 7 October 2021

Publisher's Note: MDPI stays neutral with regard to jurisdictional claims in published maps and institutional affiliations.

Copyright: (c) 2021 by the authors. Licensee MDPI, Basel, Switzerland. This article is an open access article distributed under the terms and conditions of the Creative Commons Attribution (CC BY) license (https:/ / creativecommons.org/licenses/by/ $4.0 /)$.

\author{
Nanomaterials and Nanotechnology Center, Electronic Convergence Division, Korea Institute of Ceramic \\ Engineering and Technology (KICET), 101, Soho-ro, Jinju-si 52851, Gyeongsangnam-do, Korea; \\ ichoijy@naver.com (J.Y.C.); pyop4869@naver.com (I.P.P.) \\ * Correspondence: soowon.heo@kicet.re.kr; Tel.: +82-55-792-2679
}

\begin{abstract}
We have developed a novel structure of ultra-flexible organic photovoltaics (UFOPVs) for application as a power source for wearable devices with excellent biocompatibility and flexibility. Parylene was applied as an ultra-flexible substrate through chemical vapor deposition. Indium-zinctin oxide (IZTO) thin film was used as a transparent electrode. The sputtering target composed of 70 at. $\% \mathrm{In}_{2} \mathrm{O}_{3}-15$ at. $\% \mathrm{ZnO}-15$ at. $\% \mathrm{SnO}_{2}$ was used. It was fabricated at room temperature, using pulsed DC magnetron sputtering, with an amorphous structure. UFOPVs, in which a $1 \mathrm{D}$ grating pattern was introduced into the hole-transport and photoactive layers were fabricated, showed a $13.6 \%$ improvement (maximum power conversion efficiency (PCE): $8.35 \%$ ) compared to the reference device, thereby minimizing reliance on the incident angle of the light. In addition, after 1000 compression/ relaxation tests with a compression strain of 33\%, the PCE of the UFOPVs maintained a maximum of $93.3 \%$ of their initial value.
\end{abstract}

Keywords: ultra-flexible organic solar cells; IZTO; transparent electrode; mechanical stability; 1D grating pattern

\section{Introduction}

Recently, interest in human implantable sensors, skin-attached sensors, and wearable display devices that display acquired information in real time for fast and accurate monitoring of biosignals has been increasing [1-4]. When these devices are implanted or attached to the human body, they must be ultra-light-weight and flexible so that there is no heterogeneity on the skin or other human tissues $[5,6]$. Furthermore, it is also necessary to develop new device structures, such as ones with the sensor and power-supply units combined, as well as the development of power sources for the sensors [1,4,7]. Ultra-flexible organic photovoltaics (UFOPVs) are devices that convert light-energy into electrical energy. They are one of the important candidates for use as a power source for wearable devices such as biosensors [8-11]. UFOPVs exhibit a high signal-to-noise ratio because they have a lower noise current than batteries or conventional power supplies. Therefore, when applied to biosensors, improving the accuracy of the collection and analysis of biosignals is possible [1]. In addition, due to the thickness of UFOPVs not exceeding $5 \mu \mathrm{m}$, they have excellent adaptability to skin and other tissues given their flexibility and adhesion to 3D surfaces [12]. Therefore, in order to apply UFOPVs as power sources for wearable devices, such as implantable or attachable biosensors, the following conditions must be satisfied. First, the used transparent electrode must have excellent transmittance and conductivity, as well as mechanical flexibility [13]. Second, for the stable power supply, the dependence on incident light should be low [14]. Third, since various types of organic materials (substrate, photoactive layer, electrode, etc.) are used, the device manufacturing process is better at room temperature. Fourth, the fabricated device must have excellent 
mechanical stability $[15,16]$. Currently, indium-tin oxide (ITO) transparent electrodes are being applied to various optoelectronic devices, such as liquid crystal displays (LCDs), organic light-emitting diodes (OLEDs), organic photovoltaics (OPVs), and perovskite solar cells due to their excellent transmittance and conductivity [17-20]. However, in order to improve the electro-optical properties of ITO, a thermal treatment process of $300{ }^{\circ} \mathrm{C}$ or higher is required, which makes it difficult to apply to organic-based ultra-flexible substrates [21]. In addition, due to the brittle properties of ITO, cracks or fractures occur with only $2-3 \%$ deformation $[22,23]$. Therefore, the use of organic material-based transparent electrodes with excellent mechanical stability—such as poly (3,4-ethylenedioxythiophene): polystyrene sulfonate (PEDOT:PSS), metal nanowires or meshes, carbon nanotubes and graphene-is increasing [24-27]. However, due to their low conductivity, poor surface roughness, and complicated manufacturing process compared to ITO, further research on alternative materials to replace ITO is required. Therefore, in this study, we used parylene as an ultra-flexible substrate and amorphous indium-zinc-tin oxide (IZTO) as a transparent electrode, respectively, to fabricate UFOPVs as a power source that satisfies the various aforementioned conditions. Although the results of using IZTO for various purposes has been explored by other researchers, no study evaluating its mechanical properties using transparent electrodes for UFOPVs [28-30] had been done. Parylene has excellent optical transmittance $(>90 \%)$, thermal stability $\left(>290^{\circ} \mathrm{C}\right)$, and chemical stability, making it suitable as an ultra-flexible substrate material $[1,12,31]$. The IZTO transparent electrode was fabricated using a sputtering target composed of 70 at. $\% \mathrm{In}_{2} \mathrm{O}_{3}-15$ at. $\% \mathrm{ZnO}-15$ at. $\%$ $\mathrm{SnO}_{2}$ and deposited by pulsed DC magnetron sputtering system. The IZTO transparent electrode fabricated at room temperature showed an amorphous structure, a transmittance of $88.5 \%$ (including parylene substrate) in the visible wavelength region, and a mobility of $35 \mathrm{~cm}^{2} /$ vs. In addition, to reduce the dependence on the incident angle of light, soft imprinting lithography was applied to introduce a 1D grating pattern into the hole transport layer and the photoactive layer, respectively. All UFOPVs were fabricated at room temperature with conventional structures. After introducing the 1D grating pattern, the dependence of the incident angle of light in UFOPVs decreased by 2.2 times at $80^{\circ}$. In addition, to measure the mechanical stability of UFOPVs, they were attached to an elastomer film stretched by $200 \%$, with compression/relaxation repeated 1000 times at $33 \%$ compressive strain. After the mechanical property test, the power conversion efficiency (PCE) of the UFOPVs using the IZTO transparent electrode showed a 30\% improvement compared to a device using the ITO transparent electrode.

\section{Materials and Methods}

\subsection{Materials}

Parylene, an ultra-flexible substrate material, was purchased from KISCO Ltd. (diX-SR, Tokyo, Japan) and used without further purification. The composition of the IZTO target for transparent electrode was 70 at. $\% \mathrm{In}_{2} \mathrm{O}_{3}-15$ at. $\% \mathrm{ZnO}-15$ at. $\% \mathrm{SnO}_{2}$ and was purchased from Kojundo Chemical Laboratory Co., Ltd. (Saitama, Japan). For the PEDOT:PSS used as the hole transport layer, AI4083 (Ossila) was chosen. The electron donor polymer (PTB7) and electron acceptor material $\left(\mathrm{PC}_{71} \mathrm{BM},>99 \%\right)$ were purchased from 1-material (Tokyo, Japan) and Solenne (Groningen, the Netherlands), respectively. Sylgard 184, a polydimethylsiloxane (PDMS) produced by Dow Corning (Midland, MI, USA), was used for the soft-patterned stamp.

\subsection{Fabrication of $1 D$ Grating Patterned PDMS}

To fabricate a patterned PDMS stamp with a 1D grating structure, a blank DVD was used. We discussed in detail how to fabricate a patterned PDMS stamp in a previous study [8]. The polycarbonate protective layer of the blank DVD was removed using a surgical knife. When the pattern was exposed, the dye layer was removed with methanol, then dried out using a $\mathrm{N}_{2}$ gun. For the PDMS blend solution, a base material and curing agent were mixed in a weight ratio of 10:1, then degassed in a vacuum chamber. The 
prepared PDMS solution was poured onto the DVD and cured for $3 \mathrm{~h}$ on a hot plate at $90^{\circ} \mathrm{C}$. After the PDMS had solidified, it was peeled off from the DVD and used as the 1D grating patterned PDMS stamp. The period of the 1D grating pattern was $760 \mathrm{~nm}$; the depth was $100 \mathrm{~nm}$.

\subsection{Preparation of Ultra-Flexible Substrate and IZTO Transparent Electrode}

In order to easily delaminate parylene, an ultra-flexible substrate, from the sacrificial substrate, a self-assembly monolayer (SAM) for lowering the surface energy of the sacrificial substrate was formed. The sacrificial substrate was treated with UV/Ozone (Ahtech LTS Co., Ltd., Gyeonggi-do, Korea) for $30 \mathrm{~min}$ and a small Petri dish was placed in a container with a capacity of $300 \mathrm{~mL}$. After that, $30 \mu \mathrm{L}$ of trichloro(perfluorooctyl)silane (FOTS, 98\%, Merck, Darmstadt, Germany) was dropped onto the Petri dish and the container lid was closed. It was then placed in a vacuum chamber of $5 \times 10^{-3}$ Torr for $1 \mathrm{~h}$. To fabricate a parylene ultra-flexible substrate, a SAM-treated sacrificial substrate was placed in a CVD chamber and filled with $10 \mathrm{~g}$ of parylene. A $1 \mu \mathrm{m}$ ultra-flexible substrate was fabricated by its deposition in a CVD chamber of $5 \times 10^{-4}$ Torr for $1 \mathrm{~h}$. UVO treatment was performed for $10 \mathrm{~min}$ to improve the adhesion between the parylene and IZTO transparent electrode. The prepared substrate was loaded in a sputtering chamber. Sputtering was performed with $125 \mathrm{~W}$ input power, $30 \mathrm{kHz}$ frequency, and $6 \mathrm{mTorr}$ oxygen partial pressure, with a flow ratio of $3 \%\left[\mathrm{O}_{2} /\left(\mathrm{O}_{2}+\mathrm{Ar}\right)\right]$. The deposition temperature was performed at room temperature. The thickness of the deposited IZTO film was $100 \mathrm{~nm}$.

\subsection{Fabrication of Ultra-Flexible OPVs}

UFOPVs were fabricated with a 1D grating pattern applied to the hole transport layer (PEDOT:PSS), the photoactive layer, and again on both layers. For the device without patterns, $150 \mu \mathrm{L}$ of PEDOT:PSS was applied and spin-coated at $3000 \mathrm{rpm}$ for $30 \mathrm{~s}$. Thermal annealing was performed on a hot plate at $140{ }^{\circ} \mathrm{C}$ for $20 \mathrm{~min}$, with a fabricated thickness of $40 \mathrm{~nm}$. In order to introduce a pattern to the PEDOT:PSS layer, $100 \mu \mathrm{L}$ of PEDOT:PSS was applied and spin-coated at $5000 \mathrm{rpm}$ for $10 \mathrm{~s}$. The patterned PDMS was then quickly but gently placed on the coated PEDOT:PSS layer. After $60 \mathrm{~s}$, the patterned PDMS stamp was removed and thermal annealed on a hot plate at $140{ }^{\circ} \mathrm{C}$ for $20 \mathrm{~min}$. The period of the fabricated 1D grating pattern was $760 \mathrm{~nm}$ and the depth $35 \mathrm{~nm}$. To form the photoactive layer, $\mathrm{PTB} 7$, as an electron donor material, and $\mathrm{PC}_{71} \mathrm{BM}$, as an electron acceptor material, were used, dissolved in $1 \mathrm{~mL}$ of o-dichlorobenzene (DCB) at a weight ratio of 1:1.5 (10 mg:15 mg). Three volume percent of 1,8-diiodooctane (DIO, 98\%, Merck) was added as a processing additive. The photoactive solution was spin-coated on a PEDOT:PSS layer, with or without a pattern, at $800 \mathrm{rpm}$ for $7 \mathrm{~s}$, then put in a $\mathrm{N}_{2}$-filled glove box. To form a nanostructure, the patterned PDMS was gently placed on the spin-coated photoactive layer, then removed after $60 \mathrm{~s}$. Like the PEDOT:PSS layer, no pressure was applied to the patterned PDMS; even after the patterning process, the photoactive layer was not thermally treated. The period of the fabricated 1D grating pattern was $760 \mathrm{~nm}$ and the depth $55 \mathrm{~nm}$. For the metal electrode, a thermal evaporator was used. A Ca electron transport layer $\left(0.5 \AA \mathrm{s}^{-1}, 20 \mathrm{~nm}\right)$ and an $\mathrm{Al}$ electrode $\left(0.5 \AA \mathrm{s}^{-1}, 100 \mathrm{~nm}\right)$ were deposited under a vacuum of $10^{-7}$ Torr, using a metal mask.

\subsection{Measurements}

The thicknesses of the prepared parylene thin film, IZTO, PEDOT:PSS, and photoactive layers were measured using a surface profiler (DEKTAK 6M, Bruker, Billerica, MA, USA). The transmittance of the IZTO transparent electrode was measured using UV-Vis spectroscopy (V-650, JASCO, Tokyo, Japan). The X-ray diffraction (XRD) pattern of the IZTO film was analyzed with a Rigaku SmartLab diffractometer. Monochromatic $\mathrm{Cu} \mathrm{K} \alpha$ radiation $(\lambda=0.154 \mathrm{~nm})$ was generated at $45 \mathrm{kV}, 200 \mathrm{~mA}$. The surface morphologies of the patterned PDMS, PEDOT:PSS, photoactive layer, and IZTO were observed using an AFM (5400 scanning probe microscope, Agilent Technologies, Santa Clara, CA, USA) in 
the tapping mode. The surface morphology of the IZTO film was characterized using a field emission scanning electron microscope (FESEM S-4800, Hitachi, Tokyo, Japan). Electrical properties, such as resistivity, carrier concentration, and mobility of the IZTO film, were measured using the van der Pauw method, together with a Hall measuring system (HMS-3000, Ecopia, Gyeonggi-do, Korea).

The UFOVPs' current density-voltage characteristics were measured using a Keithley 2400 source meter unit under simulated solar illumination (AM 1.5, $100 \mathrm{~mW} \mathrm{~cm}^{-2}$ ) in a $150 \mathrm{~W}$ Xe lamp -based solar simulator (PEC-L11, Peccell Technologies, Yokohama, Japan). The light intensity was calibrated with a standard silicon solar cell (BS520, Bunkoh-Keiki, Tokyo, Japan). The active area of each device was defined, using a metal photomask, to be $0.12 \mathrm{~cm}^{2}$. The external quantum efficiency (EQE) of each device was measured with monochromatic light (SM-250F, Bunkoh-Keiki, Tokyo, Japan). For the mechanical stability test of the UFOPVs, they were removed from a sacrificial substrate and attached to a $200 \%$ pre-stretched acrylic-elastomer film (VHB Y-4905 J, 3M, Saint Paul, MN, USA). The degree of stretching was controlled using a home-made uniaxial screw machine and ruler, and the measurements were conducted under simulated solar illumination (AM 1.5, $100 \mathrm{~mW} \mathrm{~cm}^{-2}$ ) and ambient conditions. The pre-stretched acrylic elastomer film, to which the ultra-flexible OPV devices were attached, was slowly compressed in the uniaxial center direction, while reducing the stretching force. This mechanical test was conducted for 1000 repeated compression cycles, with a compression of $33 \%$. The data obtained from the stretching test were recorded using a Keithley 2400 source meter unit.

\section{Results and Discussion}

Figure 1 shows the UV-visible spectroscopy data of bare glass substrate, parylene ultra-flexible substrate, and IZTO transparent electrodes deposited at room temperature. IZTO was deposited on parylene at room temperature. The transmittance of the bare glass substrate in the visible wavelength region $(380-780 \mathrm{~nm}$ ) was $92 \%$, whereas the transmittance of the parylene ultra-flexible substrate was $92.4 \%$, which was slightly higher than bare glass substrate [32]. As can be seen in Figure 1, the spectra of the parylene substrate with the IZTO transparent electrode has a sinusoidal shape. This is because the parylene substrate is very thin $(1 \mu \mathrm{m})$ and also because of the optical interference caused by the refractive index difference between the parylene substrate and air interface, or that of the parylene substrate and IZTO interface. An interesting point is that even without thermal treatment of the substrate, the IZTO/parylene transparent electrode showed a slightly higher transmittance of $88.5 \%$, which was improved compared to the ITO/parylene transparent electrode $(88 \%)$.

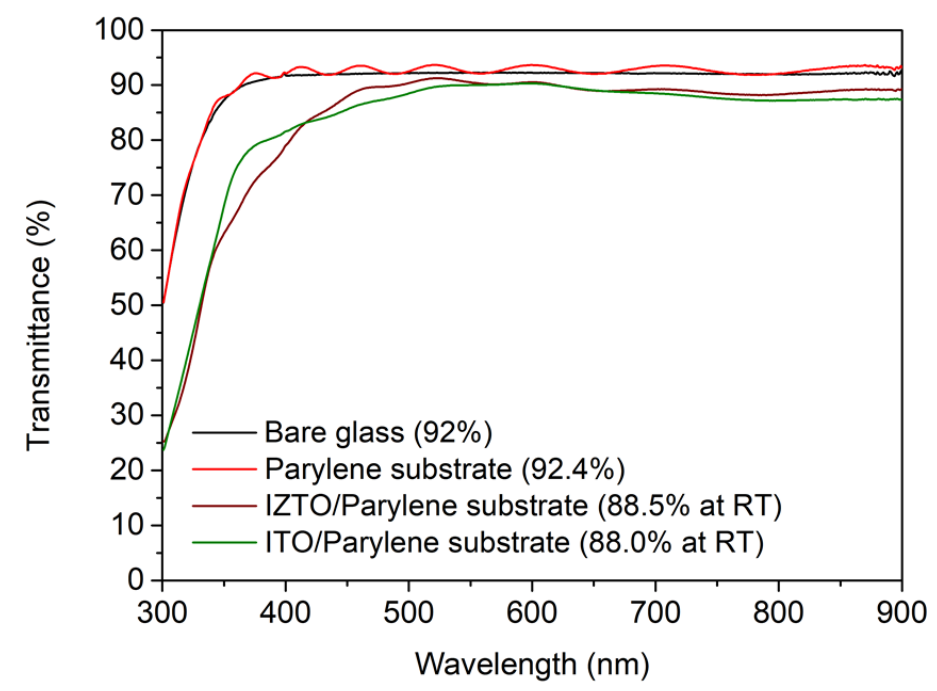

Figure 1. Transmission spectra of the bare glass, parylene free-standing film, the IZTO, and ITO films grown at room temperatures on the parylene substrates, respectively. 
Figure 2 shows the XRD pattern of IZTO deposited at room temperature. The inset shows the surface morphologies of the IZTO thin film observed by FESEM and AFM. Combining the data in Figure 2, it can be seen that IZTO deposited at room temperature has an amorphous structure and a very low surface roughness of $0.521 \mathrm{~nm}$. The resistivity, carrier concentration, and mobility of the IZTO thin film measured by the Hall measurement system were $6.2 \times 10^{-4} \Omega \mathrm{cm}, 7.0 \times 10^{20} \mathrm{~cm}^{-3}$, and $45 \mathrm{~cm}^{2} \mathrm{~V}^{-1} \mathrm{~s}^{-1}$, respectively, showing superior properties than the electrical properties of ITO fabricated at room temperature (resistivity: $8.3 \times 10^{-4} \Omega \mathrm{cm}$, carrier concentration: $5.3 \times 10^{20} \mathrm{~cm}^{-3}$ and mobility: $35 \mathrm{~cm}^{2} \mathrm{~V}^{-1} \mathrm{~s}^{-1}$ ). Therefore, it was possible to conclude that the ultra-flexible transparent electrode based on IZTO can be used as the transparent electrode of a wearable device.

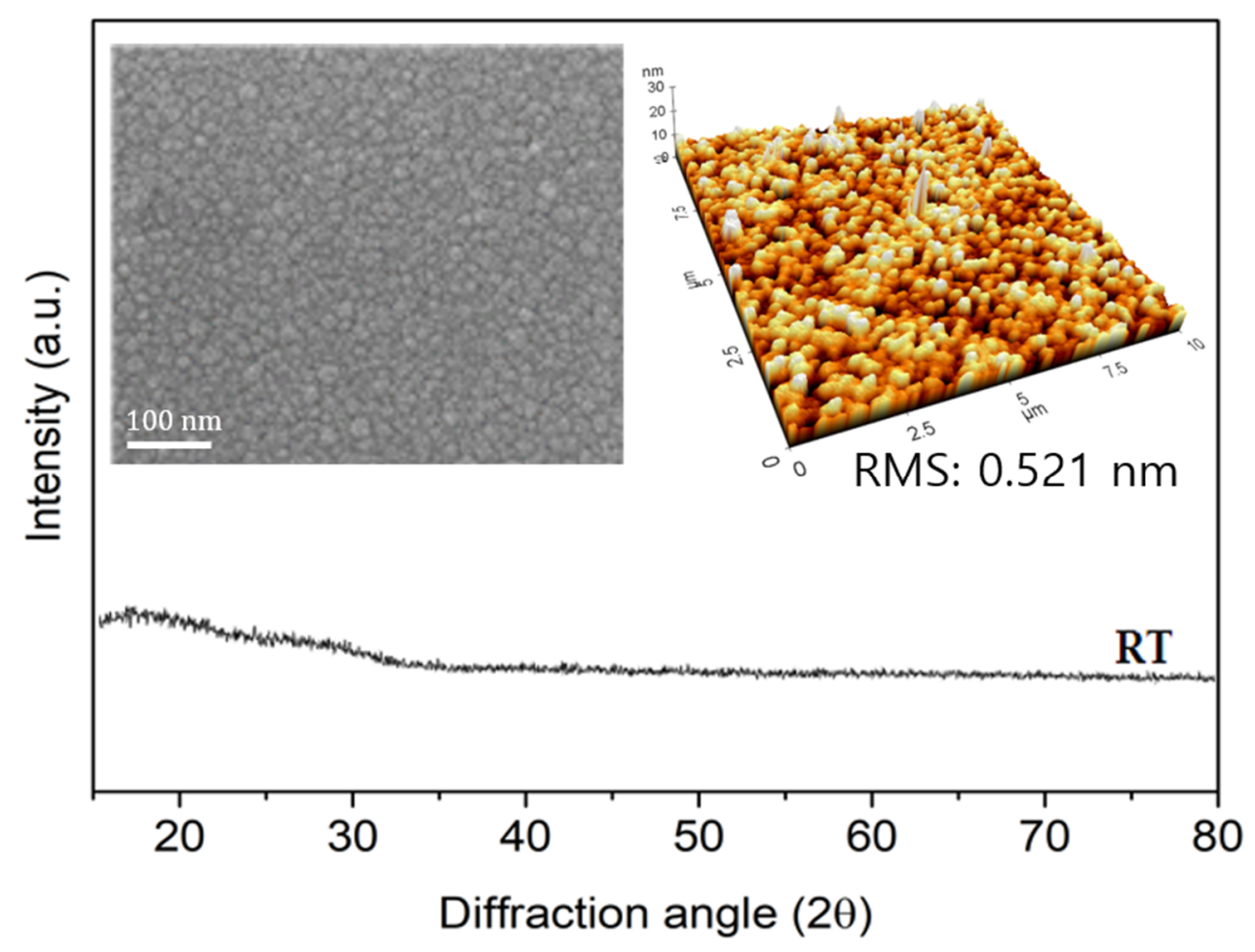

Figure 2. X-ray diffraction patterns of IZTO films with room temperature deposition on a parylene substrate. Insets are SEM image (left) and surface roughness (right) of IZTO film, respectively.

The fabrication process of the UFOPVs-with the structure of IZTO/PEDOT:PSS (with pattern (p-PEDOT) and without (f-PEDOT), $40 \mathrm{~nm}$ )/PTB7:PC $71 \mathrm{BM}$ (with pattern (p-Al) and without (f-Al), $100 \mathrm{~nm}) / \mathrm{Ca}(20 \mathrm{~nm}) / \mathrm{Al}$ electrode $(100 \mathrm{~nm})$-is shown in Figure 3. Nanostructures were introduced using a blank DVD template by applying soft imprinting lithography at room temperature. The surface morphology of the UFOPVs with nanostructures was characterized by AFM and is summarized in the inset of Figure $3 \mathrm{a}-\mathrm{c}$. The detailed IZTO-based UFOPVs' fabrication method is described in Section 2.4. The 1D grating structure in the patterned PDMS stamp had a period of about $760 \mathrm{~nm}$ and a depth of $100 \mathrm{~nm}$ (Figure 3a). In PEDOT:PSS introduced through soft nanoimprinting lithography, the period of the 1D grating structure was the same as that of the PDMS stamp, and the depth was $35 \mathrm{~nm}$ (Figure 3b). Similarly, the period of the 1D grating structure in the photoactive layer was $760 \mathrm{~nm}$ and the depth $55 \mathrm{~nm}$ (Figure 3c). Figure 3d,e shows the chemical structures of the electron donor material and the electron acceptor material used in this study, respectively. 


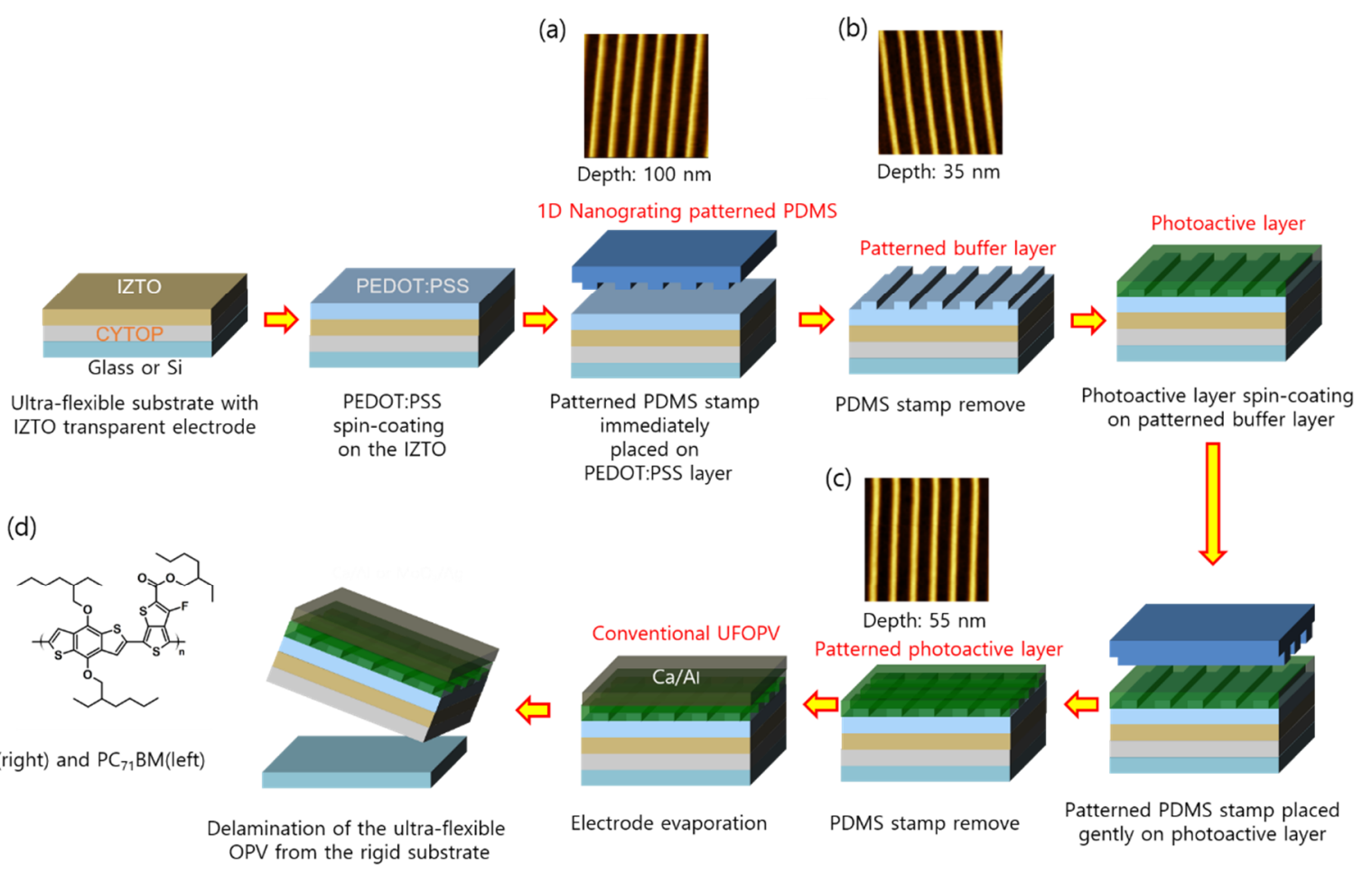

Figure 3. Schematic illustration of the fabrication of ultra-flexible OPVs with a 1D grating pattern by soft imprinting lithography using a PDMS mold. Inset figures present: (a) 1D grating patterned PDMS mold (period: $760 \mathrm{~nm}$, depth: $100 \mathrm{~nm}$ ); (b) 1D grating patterned PEDOT:PSS layer (period: $760 \mathrm{~nm}$, depth: $35 \mathrm{~nm}$ ); (c) 1D grating patterned photoactive layer; mixture of PTB7 and PC 71 BM (pitch: $760 \mathrm{~nm}$, depth: $55 \mathrm{~nm}$ ); (d,e), chemical structures of PTB7 and PC 71 BM, respectively.

Figure 4a shows the current density-voltage (J-V) characteristics of the IZTO-based UFOPVs. Detailed electrical properties, such as short circuit current density (JSC), open circuit voltage $\left(\mathrm{V}_{\mathrm{OC}}\right)$, fill factor $(\mathrm{FF})$, and power conversion efficiency (PCE) are summarized in Table 1. The $\mathrm{J}_{\mathrm{SC}}$ of the device in which the nanostructure was introduced into PEDOT:PSS (p-PEDOT/f-Al) was $15.08 \mathrm{~mA} \mathrm{~cm}{ }^{-2}$, which was better than the reference device's ( $\mathrm{f}-$ $\mathrm{PEDOT} / \mathrm{f}-\mathrm{Al}$ ) $14.83 \mathrm{~mA} \mathrm{~cm}^{-2}$. In addition, the $\mathrm{FF}$ of the $\mathrm{p}$-PEDOT $/ \mathrm{f}-\mathrm{Al}$ structure device was $69.3 \%$, slightly better than the reference device $(68.0 \%)$. All $\mathrm{V}_{\mathrm{OC}}$ were $0.72 \mathrm{~V}$, with no significant change. With the increase of the JSC and FF, the PCE of the device of the p-PEDOT / f-Al structure was improved by $3.6 \%$ from $7.26 \%$ (reference device) to $7.52 \%$. When a $1 \mathrm{D}$ grating pattern was introduced into the photoactive layer (f-PEDOT/p-Al), the $\mathrm{J}_{\mathrm{SC}}$ value increased to $16.05 \mathrm{~mA} \mathrm{~cm}^{-2}$, with ignorable change in the $\mathrm{V}_{\mathrm{OC}}$ and $\mathrm{FF}$, and the calculated PCE showing $7.95 \%$. In addition, when $1 \mathrm{D}$ grating patterns were introduced in both the PEDOT:PSS and photoactive layer (p-PEDOT/p-Al), $\mathrm{V}_{\mathrm{OC}}$ stayed at $0.72 \mathrm{~V}$, while $\mathrm{J}_{\mathrm{SC}}$ increased to $16.81 \mathrm{~mA} \mathrm{~cm}^{-2}$, showing the highest PCE of $8.35 \%$.

Table 1. Device characteristics of various device structures. The average values were calculated from eight or more cells. $\mathrm{R}_{\mathrm{SH}}$ and $\mathrm{R}_{\mathrm{S}}$ were obtained from the slope of the J-V curves in the dark at 0 and $1 \mathrm{~V}$, respectively.

\begin{tabular}{|c|c|c|c|c|c|c|c|c|}
\hline \multicolumn{2}{|c|}{ Device Structure } & $\begin{array}{c}\mathrm{JSC}_{\mathrm{SC}} \\
\left(\mathrm{mA}^{-2} \mathrm{~cm}^{-2}\right)\end{array}$ & $\begin{array}{l}\mathrm{V}_{\text {OC }} \\
\text { (V) }\end{array}$ & $\begin{array}{l}\text { FF } \\
(\%)\end{array}$ & $\begin{array}{l}\text { PCE } \\
(\%)\end{array}$ & $\begin{array}{c}\text { Increment in PCE } \\
(\%)\end{array}$ & $\begin{array}{c}\mathrm{R}_{\mathrm{SH}} \\
\left(\mathrm{k} \Omega \mathrm{cm}^{2}\right)\end{array}$ & $\begin{array}{c}R_{S} \\
\left(\Omega \mathrm{cm}^{2}\right)\end{array}$ \\
\hline \multirow{4}{*}{ IZTO } & $\begin{array}{c}\text { Reference } \\
\text { (f-PEDOT/f-Al) }\end{array}$ & $14.83 \pm 0.02$ & 0.72 & $68.0 \pm 0.2$ & $7.26 \pm 0.3$ & - & 4.1 & 3.51 \\
\hline & p-PEDOT/f-Al & $15.08 \pm 0.06$ & 0.72 & $69.3 \pm 0.3$ & $7.52 \pm 0.2$ & 3.6 & 9.9 & 2.78 \\
\hline & f-PEDOT/p-Al & $16.05 \pm 0.04$ & 0.72 & $68.8 \pm 0.2$ & $7.95 \pm 0.4$ & 8.1 & 9.0 & 2.74 \\
\hline & p-PEDOT/p-Al & $16.81 \pm 0.06$ & 0.72 & $69.0 \pm 0.2$ & $8.34 \pm 0.3$ & 13.6 & 15.3 & 2.32 \\
\hline ITO & p-PEDOT/p-Al & $17.07 \pm 0.03$ & 0.72 & $68.9 \pm 0.3$ & $8.58 \pm 0.2$ & - & 15.8 & 2.22 \\
\hline
\end{tabular}



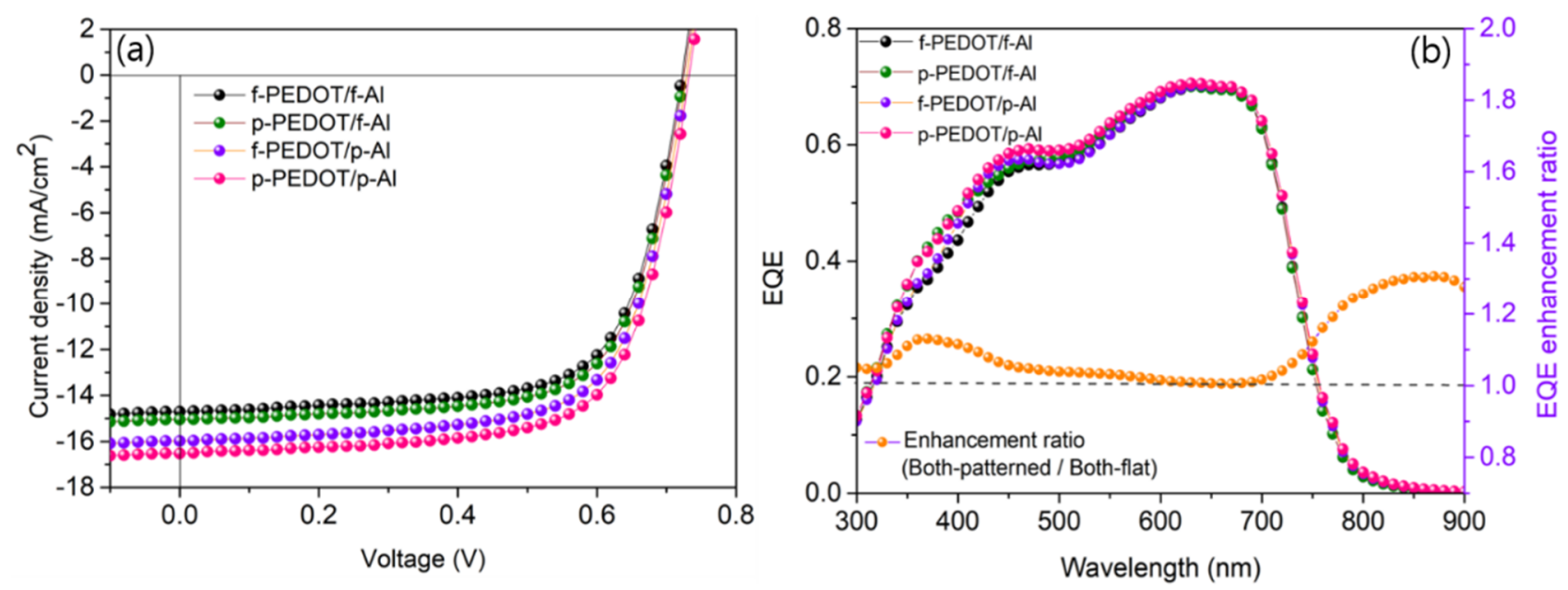

Figure 4. J-V characteristics of ultra-flexible OPVs based on PTB7:PC 71 BM BHJ with (a) f-PEDOT/f-Al, p-PEDOT/f-Al, $\mathrm{f}-\mathrm{PEDOT} / \mathrm{p}-\mathrm{Al}$, and p-PEDOT/p-Al. J-V characteristics of UFOPVs measured under AM 1.5G illumination at $100 \mathrm{~mW} \mathrm{~cm}^{-2}$.

(b) EQE spectra and EQE enhancement ratios of the patterned devices relative to the reference.

As can be seen in Table 1, when the 1D grating pattern was introduced into both the PEDOT:PSS and the photoactive layer, the series resistance $\left(R_{S}\right)$ and shunt resistance $\left(R_{S H}\right)$ values both improved compared to the reference device. The FF and JS increased by $1.5 \%$ and $13.4 \%$, respectively. In addition, when the $1 \mathrm{D}$ grating pattern was introduced into the PEDOT:PSS layer, transmittance in the 300-450 nm wavelength region was improved due to the anti-reflection effect. Figure $4 \mathrm{~b}$ shows that the EQE value in the $300-450 \mathrm{~nm}$ wavelength region was better than the reference device. Therefore, it can be seen that the introduction of nanostructures in the PEDOT:PSS layer leads to the improvement of $\mathrm{JSC}_{\mathrm{SC}}$. Furthermore, the introduction of a 1D grating pattern into the photoactive layer significantly increased the JSC to $16.05 \mathrm{~mA} \mathrm{~cm}^{-2}$ (p-PEDOT/f-Al) and $16.81 \mathrm{~mA} \mathrm{~cm}^{-2}$ (p-PEDOT/p-Al), respectively. In addition, propagating surface plasmon polariton ( $\mathrm{p}-\mathrm{SPP})$, generated at the patterned photoactive layer and metal interface, also induces the cumulative gain of JSC. This can be confirmed by observing the wavelength region after $700 \mathrm{~nm}$ in Figure $4 \mathrm{~b}$. Finally, when a 1D grating pattern was introduced in all layers, JSC increased to $16.81 \mathrm{~mA} \mathrm{~cm}^{-2}$, showing the highest PCE of $8.35 \%$, due to the combined effects of anti-reflection, scattering, and propagating surface plasmon polariton.

Figure 5 shows the data analyzing the PCE characteristics of the UFOPVs with respect to the incident angle of light. It was confirmed that the device in which the nanostructure was introduced had a reduced dependence on incident light compared to the device without the nanostructure. This is because the incident light is scattered by the $1 \mathrm{D}$ grating pattern formed between the PEDOT:PSS layer and the photoactive layer, thereby increasing the optical path length. Therefore, the absorption amount of photons at a low incident angle is increased compared to a device without a nanostructure. When the incident angle was $80^{\circ}$, the PCE of UFOPVs with nanostructures was improved by 2.2 times compared to the reference device. This demonstrates that UFOPVs with nanostructures can be used as power sources for wearable devices. 


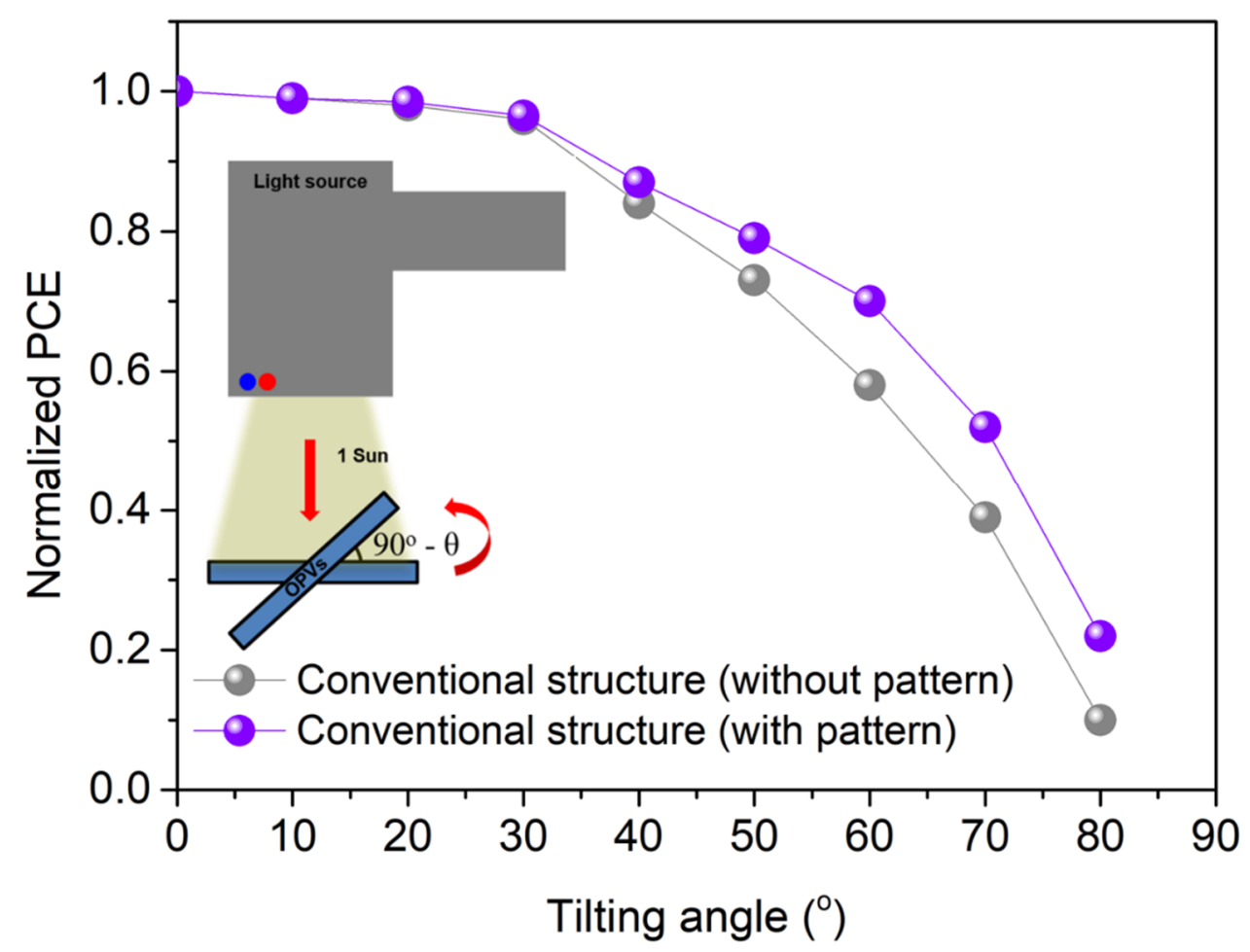

Figure 5. Incident angle dependence characteristics of with/without patterned ultra-flexible OPVs. Data shows normalized values of PCE. Inset shows the illustration of incident angle of light.

To confirm the mechanical stability of IZTO/parylene-based UFOPVs, repeated compression tests were performed. The UFOPVs delaminated from the sacrificial substrate were attached to a $200 \%$ pre-stretched acrylic elastomer film. UFOPVs fixed on an elastomer film were compressed in a uniaxial direction. Compression and relaxation were repeated 1000 times at a compression strain of $33 \%$ and their results are summarized in Table 2. In the case of IZTO-based UFOPVs, the PCE decreased by $6.7 \%$, from $8.3 \%$ to $7.8 \%$. On the other hand, in the case of UFOPVs using ITO as a transparent electrode, the PCE decreased by $43 \%$, from $8.6 \%$ to $6 \%$. As can be seen in Figure $6 a-c$, the PCE of the ITO-based device decreased due to the reduction of $\mathrm{JSC}_{\mathrm{SC}}$ and FF. On the other hand, the decrease in $\mathrm{J}_{\mathrm{SC}}$ and FF was not noticeable in the IZTO-based device due to the high brittleness of ITO. It was confirmed that the amorphous IZTO showed excellent mechanical stability despite the test's harsh conditions. In addition, by using flexible PEDOT:PSS as a hole transport layer, it is expected that PEDOT:PSS would resist deformation, thereby playing a role in protecting the IZTO transparent electrode.

Table 2. Device characteristics of various device structures after mechanical test.

\begin{tabular}{|c|c|c|c|c|c|}
\hline \multicolumn{2}{|c|}{ Device Structure } & $\begin{array}{c}\mathrm{JSC}_{\mathrm{SC}} \\
\left(\mathrm{mA} \mathrm{cm}^{-2}\right)\end{array}$ & $\begin{array}{l}\mathrm{V}_{\text {OC }} \\
\text { (V) }\end{array}$ & $\begin{array}{l}\text { FF } \\
(\%)\end{array}$ & $\begin{array}{l}\text { PCE } \\
(\%)\end{array}$ \\
\hline \multirow{2}{*}{ After mechanical test } & ITO & 13.69 & 0.71 & 61.8 & 6.01 \\
\hline & IZTO & 16.01 & 0.71 & 68.2 & 7.75 \\
\hline
\end{tabular}



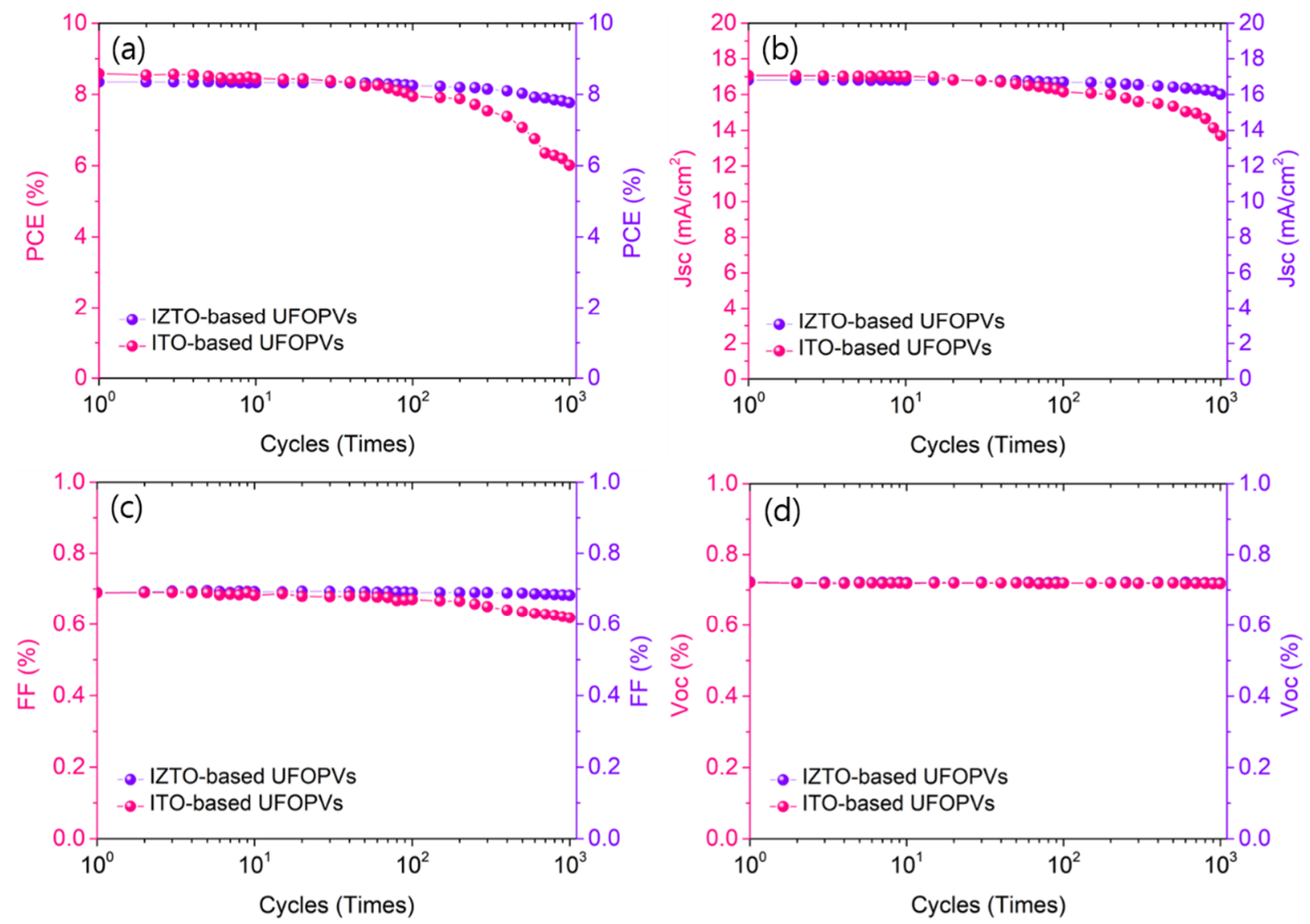

Figure 6. Behavior of photovoltaic parameters under cyclic compression of ultra-flexible OPVs with ITO, and ultra-flexible OPVs with IZTO: (a) PCE, (b) JSC, (c) FF, and (d) Voc.

\section{Conclusions}

We successfully fabricated $1 \mu \mathrm{m}$-thick UFOPVs that were highly compatible with the human body and capable of supplying stable energy. The substrate of UFOPVs used parylene, and the IZTO used as the transparent electrode was fabricated at room temperature through pulsed DC magnetron sputtering system using a sputtering target composed of 70 at. $\% \mathrm{In}_{2} \mathrm{O}_{3}-15$ at. $\% \mathrm{ZnO}-15$ at. $\% \mathrm{SnO}_{2}$. The $1 \mu \mathrm{m}$-thick parylene, ultra-flexible substrate showed a high transmittance of $92.4 \%$. The IZTO/parylene-based transparent electrode, to which IZTO deposited at room temperature was applied, has an amorphous structure and a demonstrated transmittance of $88.5 \%$. In addition, the resistivity, carrier concentration, and mobility were $6.2 \times 10^{-4} \Omega \mathrm{cm}, 5.3 \times 10^{20} \mathrm{~cm}^{-3}$, and $35 \mathrm{~cm}^{2} \mathrm{~V}^{-1} \mathrm{~s}^{-1}$, respectively.

In addition, we introduced a 1D grating pattern on the hole transport and photoactive layers through soft imprinting lithography at room temperature to lower the dependence on the incident angle of light and thereby obtain higher output power. The fabricated device showed a PCE of $8.35 \%$, which is an improvement of $13.6 \%$ compared to the reference device. With the introduction of the 1D grating pattern, anti-reflection, scattering, and propagation surface plasmon polaritons were expressed in a complex manner, causing the cumulative accumulation of $\mathrm{JSC}_{\mathrm{SC}}$. Moreover, with the introduction of the 1D grating pattern, the dependence on the incident angle of light was reduced by 2.2 times at $80^{\circ}$. IZTO/parylene-based UFOPVs also showed very good mechanical stability. Although compression-relaxation was repeated 1000 times with a compression strain of $33 \%$, there was only a $6.7 \%$ decrease compared to the initial PCE. Therefore, IZTO/parylene-based, ultra-flexible, transparent electrodes can be used for future optoelectronic devices. Furthermore, fabricated UFOPVs can be combined with various wearable devices, as well as used self-powered devices that do not require an external power source. 
Author Contributions: S.W.H. conceived and designed the research. J.Y.C. and I.P.P. fabricated the ultra-thin substrate, OPVs, and performed electrical/optical measurements. J.Y.C. and S.W.H. conducted the incident angle dependence and mechanical tests. S.W.H. analyzed and interpreted the data and prepared the manuscript. All authors have read and agreed to the published version of the manuscript.

Funding: This research was supported by the National Research Foundation of Korea (NRF) funded by the Ministry of Science and ICT (NRF-2020M3H4A3081867) and (NRF-2020R1F1A1051586). This work was also supported by the Ceramic Strategic Research Program (No.KPP20004-1) through the Korea Institute of Ceramic Engineering \& Technology (KICET).

Data Availability Statement: The data presented in this study are available on request from the corresponding author.

Conflicts of Interest: The authors declare no conflict of interest.

\section{References}

1. Park, S.; Heo, S.W.; Lee, W.; Inoue, D.; Jiang, Z.; Yu, K.; Jinno, H.; Hashizume, D.; Sekino, M.; Yokota, T.; et al. Self-powered ultra-flexible electronics via nano-grating-patterned organic photovoltaics. Nature 2018, 561, 516-521. [CrossRef]

2. Baik, S.; Lee, H.J.; Kim, D.W.; Kim, J.W.; Lee, Y.; Pang, C. Bioinspired Adhesive Architectures: From Skin Patch to Integrated Bioelectronics. Adv. Mater. 2019, 31, 1803309. [CrossRef]

3. Ray, T.R.; Choi, J.; Bandodkar, A.J.; Krishnan, S.; Gutruf, P.; Tian, L.; Ghaffari, R.; Rogers, J.A. Bio-Integrated Wearable Systems: A Comprehensive Review. Chem. Rev. 2019, 119, 5461-5533. [CrossRef]

4. Sultana, A.; Ghosh, S.K.; Sencadas, V.; Zheng, T.; Higgins, M.J.; Middya, T.R.; Mandal, D. Human Skin Interactive Self-powered Wearable Piezoelectric Bio-e-skin by Electrospun Poly-L-lactic Acid Nanofibers for Non-invasive Physiological Signal Monitoring. J. Mater. Chem. B 2017, 5, 7352-7359. [CrossRef]

5. Chun, S.; Kim, D.W.; Baik, S.; Lee, H.J.; Lee, J.H.; Bhang, S.H.; Pang, C. Conductive and Stretchable Adhesive Electronics with Miniaturized Octopus-Like Suckers against Dry/Wet Skin for Biosignal Monitoring. Adv. Funct. Mater. 2018, $28,1805224$. [CrossRef]

6. Ha, M.; Lim, S.; Ko, H. Wearable and flexible sensors for user-interactive health-monitoring devices. J. Mater. Chem. B 2018, 6, 4043-4064. [CrossRef]

7. Ghosh, S.K.; Adhikary, P.; Jana, S.; Biswas, A.; Sencadas, V.; Gupta, S.D.; Tudu, B.; Mandal, D. Electrospun gelatin nanofiber based self-powered bio-e-skin for health care monitoring. Nano Energy 2017, 36, 166-175. [CrossRef]

8. Heo, S.W.; Le, T.H.H.; Tanaka, T.; Osaka, I.; Takimiya, K.; Tajima, K. Cumulative gain in organic solar cells by using multiple optical nanopatterns. J. Mater. Chem. A 2017, 5, 10347-10354. [CrossRef]

9. Hashemi, S.A.; Ramakrishna, S.; Aberle, A.G. Recent Progress in Flexible-Wearable Solar Cells for Self-Powered Electronic Device. Energy Environ. Sci. 2020, 13, 685-743. [CrossRef]

10. Heo, S.W. Vacuum-Free Fabrication Strategies for Nanostructure-Embedded Ultrathin Substrate in Flexible Polymer Solar Cells. Energies 2020, 13, 5375. [CrossRef]

11. Heo, S.W. Ultra-Flexible Organic Photovoltaics with Nanograting Patterns Based on CYTOP/Ag Nanowires Substrate. Nanomaterials 2020, 10, 2185. [CrossRef] [PubMed]

12. Takakuwa, M.; Heo, S.W.; Fukuda, K.; Tajima, K.; Park, S.; Umezu, S.; Someya, T. Nanograting Structured Ultrathin Substrate for Ultraflexible Organic Photovoltaics. Small Methods 2020, 4, 1900762. [CrossRef]

13. Zhang, Y.; Ng, S.-W.; Lu, X.; Zheng, Z. Solution-Processed Transparent Electrodes for Emerging Thin-Film Solar Cells. Chem. Rev. 2020, 120, 2049-2122. [CrossRef] [PubMed]

14. Zhang, Y.-X.; Fang, J.; Li, W.; Shen, Y.; Chen, J.-D.; Li, Y.; Gu, H.; Pelivani, S.; Zhang, M.; Li, Y.; et al. Synergetic Transparent Electrode Architecture for Efficient Non-Fullerene Flexible Organic Solar Cells with >12\% Efficiency. ACS Nano 2019, 13, $4686-4694$. [CrossRef] [PubMed]

15. Yun, J.; Song, C.; Lee, H.; Park, H.; Jeong, Y.R.; Kim, J.W.; Jin, S.W.; Oh, S.Y.; Sun, L.; Zi, G.; et al. Stretchable array of highperformance micro-supercapacitors charged with solar cells for wireless powering of an integrated strain sensor. Nano Energy 2018, 49, 644-654. [CrossRef]

16. Varma, S.J.; Kumar, K.S.; Seal, S.; Rajaraman, S.; Thomas, J. Fiber-Type Solar Cells, Nanogenerators, Batteries, and Supercapacitors for Wearable Applications. Adv. Sci. 2018, 5, 180034. [CrossRef] [PubMed]

17. Han, Y.W.; Lee, H.S.; Moon, D.K. Printable and Semitransparent Nonfullerene Organic Solar Modules over $30 \mathrm{~cm}^{2}$ Introducing an Energy-Level Controllable Hole Transport Layer. ACS Appl. Mater. Interfaces 2021, 13, 19085-19098. [CrossRef] [PubMed]

18. Minani, T. Present status of transparent conducting oxide thin-film development for Indium-Tin-Oxide (ITO) substitutes. Thin Solid Films 2008, 516, 5822-5828. [CrossRef]

19. Han, Y.W.; Jung, C.H.; Lee, H.S.; Jeon, S.J.; Moon, D.K. High-Performance Nonfullerene Organic Photovoltaics Applicable for Both Outdoor and Indoor Environments through Directional Photon Energy Transfer. ACS Appl. Mater. Interfaces 2020, 12, 38470-38482. [CrossRef] 
20. Bett, A.J.; Winkler, K.M.; Bivour, M.; Cojocaru, L.; Kabakli, Ö.Ş.; Schulze, P.S.C.; Siefer, G.; Tutsch, L.; Hermle, M.; Glunz, S.W.; et al. Semi-Transparent Perovskite Solar Cells with ITO Directly Sputtered on Spiro-OMeTAD for Tandem Applications. ACS Appl. Mater. Interfaces 2019, 11, 45796-45804. [CrossRef]

21. Exarhos, G.J.; Zhou, X.-D. Discovery-based design of transparent conducting oxide films. Thin Solid Films 2007, 515, 7025-7052. [CrossRef]

22. Zardetto, V.; Brown, T.M.; Reale, A.; Carlo, A.D. Substrates for Flexible Electronics: A Practical Investigation on the Electrical, Film Flexibility, Optical, Temperature, and Solvent Resistance Properties. J. Polym. Sci. Part B Polym. Phys. 2011, 49, 638-648. [CrossRef]

23. Cairns, D.R.; Witte, R.P., II; Sparacin, D.K.; Sachsman, S.M.; Paine, D.C.; Crawford, G.P. Strain-dependent electrical resistance of tin-doped indium oxide on polymer substrates. Appl. Phys. Lett. 2000, 76, 1425. [CrossRef]

24. Jang, W.; Kim, B.G.; Seo, S.; Shawky, A.; Kim, M.S.; Kim, K.; Mikladal, B.; Kauppinen, E.I.; Maruyama, S.; Jeon, I.; et al. Strong dark current suppression in flexible organic photodetectors by carbon nanotube transparent electrodes. Nanotoday 2021, 37, 101081. [CrossRef]

25. Araki, T.; Uemura, T.; Yoshimoto, S.; Takemoto, A.; Noda, Y.; Izumi, S.; Sekitani, T. Wireless Monitoring Using a Stretchable and Transparent Sensor Sheet Containing Metal Nanowires. Adv. Mater. 2019, 32, 1902684. [CrossRef]

26. Kim, D.C.; Shim, H.J.; Lee, W.; Koo, J.H.; Kim, D.-H. Material-Based Approaches for the Fabrication of Stretchable Electronics. Adv. Mater. 2019, 31, 1902743. [CrossRef]

27. Kochetkov, F.M.; Neplokh, V.; Mastalieva, V.A.; Mukhangali, S.; Vorob'ev, A.A.; Uvarov, A.V.; Komissarenko, F.E.; Mitin, D.M.; Kapoor, A.; Eymery, J.; et al. Stretchable Transparent Light-Emitting Diodes Based on InGaN/GaN Quantum Well Microwires and Carbon Nanotube Films. Nanomaterials 2021, 11, 1503. [CrossRef] [PubMed]

28. Zhou, N.; Buchholz, D.B.; Zhu, G.; Yu, X.; Lin, H.; Facchetti, A.; Marks, T.J.; Chang, R.P.H. Ultraflexible Polymer Solar Cells Using Amorphous Zinc-Indium-Tin Oxide Transparent Electrodes. Adv. Mater. 2014, 26, 1098-1104. [CrossRef] [PubMed]

29. Noviyana, I.; Lestari, A.D.; Putri, M.; Won, M.-S.; Bae, J.-S.; Heo, Y.-W.; Lee, H.Y. High Mobility Thin Film Transistors Based on Amorphous Indium Zinc Tin Oxide. Materials 2017, 10, 702. [CrossRef] [PubMed]

30. Li, K.-D.; Chen, P.-W.; Chang, K.-S.; Hsu, S.-C.; Jan, D.-J. Indium-Zinc-Tin-Oxide Film Prepared by Reactive Magnetron Sputtering for Electrochromic Applications. Materials 2018, 11, 2221. [CrossRef]

31. Jean, J.; Wang, A.; Bulović, V. In situ vapor-deposited parylene substrates for ultra-thin, lightweight organic solar cells. Org. Electron. 2016, 31, 120-126. [CrossRef]

32. Darvishzadeh, A.; Alharbi, N.; Mosavi, A.; Gorji, N.E. Modeling the strain impact on refractive index and optical transmission rate. Phys. B Condens. Matter 2018, 543, 14-17. [CrossRef] 